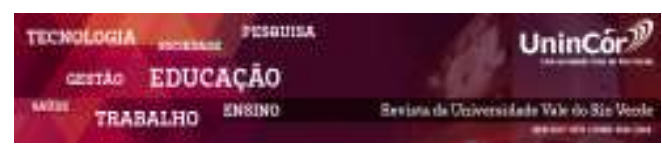

Revista da Universidade Vale do Rio Verde ISSN: 1517-0276 / EISSN: 2236-5362 Vol. 16 | n. 1 | Ano 2018

Valéria Fernandes de Oliveira Sousa Universidade Federal de Campina Grande valeriafernandesbds@gmail.com

Gisele Lopes dos Santos Universidade Federal de Campina Grande gisele1612@gmail.com

Luana Muniz de Oliveira Universidade Federal de Campina Grande luanamunizuepb@gmail.com

Marília Hortência Batista Silva Rodrigues Universidade Federal de Campina Grande marilia_agroecologa@hotmail.com

Maria Amanda Vieira de Almeida Universidade Estadual da Paraíba amanda.almeidaca2017@gmail.com

\section{A RELEVÂNCIA DO ESTÁGIO PARA O LICENCIANDO EM CIÊNCIAS AGRÁRIAS E SUA RELAÇÃO COM A FORMAÇÃO DOCENTE}

\begin{abstract}
RESUMO
O estágio supervisionado compreende uma etapa muito importante na licenciatura, visto que, é o momento de desenvolvimento intelectual associado ao prático, apresentando desta forma grande influência sobre o futuro profissional. Com isso, o objetivo deste estudo foi demonstrar a importância do estágio para o licenciando em Ciências Agrárias, proporcionando maiores informações sobre a construção da identidade profissional provocada por este processo. A referida pesquisa foi realizada com alunos do $5^{\circ}$ ao $7^{\circ}$ período do curso de licenciatura plena em Ciências Agrárias da Universidade Estadual da Paraíba no Centro de Ciências Humanas e Agrárias pertencente ao município de Catolé do Rocha-PB, durante os anos de 2015 e 2016. Esse levantamento de informações foi efetuado aplicandose um questionário com perguntas abertas para estagiários do curso com o intuito de conseguir extrair relatos de suas experiências durante e após colocarem em prática os conhecimentos adquiridos nesta etapa. Através deste estudo houve a confirmação de que o estágio é fator crucial para a construção da identidade profissional, pois força o licenciando a ser adepto a um ambiente que passa por constantes mudanças e possui ligações intrínsecas com diversos outros meios de socialização (relação professor $\mathrm{x}$ aluno, aluno $\mathrm{x}$ aluno, docente $\mathrm{x}$ conteúdo, família $\mathrm{x}$ escola e cidadão $x$ sociedade). Contudo, ainda necessita de mudanças para ampliar o leque de profissionais que concluem o curso e ingressam na carreira profissional do curso. Desta forma, o estágio prepara os licenciados em Ciências Agrárias para o futuro mercado de trabalho, bem como, para a vida.
\end{abstract}

Palavras-chave: Ambiente Educacional. Ensino-aprendizagem. Experiência Profissional. Docência. Relatos.

\section{THE RELEVANCE OF THE STAGE TO THE LICENSEE IN AGRICULTURAL SCIENCES AND ITS RELATIONSHIP WITH THE TEACHER TRAINING}

\begin{abstract}
The supervised stage comprises a very important stage in the degree, since it is the moment of intellectual development associated to the practical one, presenting in this way great influence on the professional future. With this, the objective of this study was to demonstrate the importance of the internship for the licesingin Agrarian Sciences, providing more information about the construction of the professional identity provoked by this process. This research was carried out with students from the 5 th to the 7 th year of the full degree course in Agricultural
\end{abstract}


Sciences of the State University of Paraíba at the Center of Human and Agrarian Sciences belonging to the municipality of Catolé do Rocha-PB, during the years 2015 and 2016. This information collection was carried out by applying a questionnaire with open questions for trainees of the course in order to be able to extract reports of their experiences during and after putting into practice the knowledge acquired in this stage. Through this study there was confirmation that the stage is a crucial factor for the construction of the professional identity, because it forces the licensing to be adept to an environment that undergoes constant changes and has intrinsic connections with several other means of socialization (relation professor $\mathrm{x}$ student, student $\mathrm{x}$ student, teacher $\mathrm{x}$ content, family $\mathrm{x}$ school and citizen $\mathrm{x}$ society). However, it still needs changes to expand the range of professionals who complete the course and enter the professional career of the course. In this way, the internship prepares graduates in Agrarian Sciences for the future labor market, as well as, for life.

Keywords: Educational Environment. Teaching-learning. Professional experience. Teaching. Stories.

Recebido em: 02/10/2017 - Aprovado em: 10/01/2018- Disponibilizado em: 15/07/2018

\section{INTRODUÇÃO}

Com o estágio tem-se a concepção dos desafios profissionais que iremos possivelmente encontrar na carreira docente, além da construção do perfil profissional através do compromisso, criatividade, ética, respeito e entre outras qualidades essenciais que são requisitos em qualquer profissão, principalmente a de professor, percebendo-se assim a importância desse componente curricular para a formação docente.

Segundo Pimenta e Gonçalves (1990) a finalidade do estágio é propiciar ao aluno uma aproximação à realidade na qual atuará. O estágio é importante, pois através dele o licenciando entra em contato com a sala de aula e descobre a essência do mundo escolar, com isso adquire conhecimentos práticos os quais juntamente com a teoria formarão o futuro profissional educador. O estágio é o eixo central na formação de professores, pois é através dele que o profissional conhece os aspectos indispensáveis para a formação da construção da identidade e dos saberes do dia-a-dia (PIMENTA; LIMA, 2010).

A identidade de um indivíduo é dada pela sua forma de ser, acrescida pelos seus valores. Já a identidade profissional é a que nós enquanto profissionais construímos ao longo do nosso exercício profissional. Quando o docente é estagiário ele começa sua construção de identidade, começa a experimentar o sabor de ministrar uma aula, daí acentua-se qual caminho ele deve trilhar futuramente. Sendo o primeiro passo para conhecer um novo mundo.

$\mathrm{Na}$ nova concepção de formação - do professor como intelectual crítico, como profissional reflexivo e pesquisador e elaborador de conhecimentos, como participante qualificado 
na organização e gestão da escola- o professor prepara-se teoricamente nos assuntos pedagógicos e nos conteúdos para poder realizar a reflexão sobre sua prática; atua como intelectual crítico na contextualização sociocultural de suas aulas e na transformação social mais ampla; torna-se investigador analisando suas práticas docentes, revendo as rotinas, inventando novas soluções; desenvolve habilidades de participação grupal e de tomada de decisões seja na elaboração do projeto pedagógico e da proposta curricular seja nas várias atividades da escola como execução de ações, análise de problemas, discussão de pontos de vista, avaliação de situações etc (LIBÂNEO, 2008).

O professor possui um novo papel de agente mediador do conhecimento e não apenas mero transmissor de conteúdo. Nesse contexto, o docente deve sempre se manter atualizado, pois a formação acadêmica serve apenas de subsídio para iniciar uma vida profissional necessitando sempre de formações continuadas.

$\mathrm{O}$ docente enquanto profissional necessita acatar saberes e competências que constituirão o seu cotidiano. Até porque o ato de lecionar não é exato, mas sim fluido, no sentido de ser/acontecer sempre o inesperado (por mais que você obtenha experiência em sala de aula, sempre haverá algo novo, visto que, está ensinando requer trabalhar com pessoas as quais possuem suas particularidades).

Perrenoud (2000) apresenta dez famílias de competências para ensinar: Organizar e dirigir situações de aprendizagem; administrar a progressão das aprendizagens; conceber e fazer evoluir os dispositivos de diferenciação; envolver os alunos em suas aprendizagens e em seu trabalho; trabalhar em equipe; participar da administração da escola; informar e envolver os pais; utilizar novas tecnologias; enfrentar os deveres e os dilemas éticos da profissão; administrar sua própria formação contínua.

Essas competências são magníficas, porém sabe-se que na prática se conseguir realizar $50 \%$ pode-se dizer que está realizado profissionalmente, porque infelizmente a realidade das nossas escolas, principalmente as públicas, vivenciam dificuldades na infraestrutura, professores mal remunerados, pais que não participam da vida escolar de seus filhos, alunos baderneiros, docentes exaustos com cargas horárias extrapoladas e dentre outros fatores que impossibilitam os professores (são os principais agentes transformadores nesse contexto) a simplesmente desistirem de uma educação transformadora.

Neste trabalho optou-se por entrevistar os alunos do curso de licenciatura plena em Ciências Agrárias do $5^{\circ}$ ao $7^{\circ}$ período com a finalidade de investigar a relevância do estágio para o licenciando em Ciências Agrárias a fim de proporcionar a formação da construção da identidade profissional.

\section{MATERIAL E MÉTODOS}

Para esta analise foi realizada uma pesquisa com alunos da Universidade Estadual da Paraíba no Centro de Ciências Humanas e Agrárias, do $5^{\circ}$ ao $7^{\circ}$ período do curso de licenciatura plena em Ciências Agrárias, os quais realizaram ou estavam em realização das 
atividades de estágio, durante os anos de 2015 e 2016. Esse levantamento foi realizado na cidade de Catolé do Rocha-PB a qual apresenta o referido curso.

A entrevista abordou pontos sobre $\mathrm{o}$ estágio onde abrangeu perguntas relacionadas à importância do profissional no campo de atuação, além, da contribuição do estágio para a formação da identidade profissional. Foram entrevistados 50 universitários do referente curso.

O questionário com perguntas abertas foi o instrumento de pesquisa utilizado para a coleta de dados.Este instrumento foi entregue a cada estagiário com o intuito de conseguir extrair informações acerca de suas experiências (receios e expectativas) durante e depois de colocarem em prática os conhecimentos adquiridos durante o curso.

Nesse estudo de caso, o formulário continha seis perguntas, das quais foram: $\mathrm{O}$ estágio supervisionado no curso de Licenciatura Plena em Ciências Agrárias é relevante? Ao estagiar encontrou afinidade com seu futuro campo de atuação? A metodologia da subdivisão do estágio em quatro fases (duas observações e duas intervenções) foram/são de suma importância? Gostaria de atuar também em outro campo de estágio como EMATER, empresas agrícolas ou fazendas? Quais as dificuldades encontradas durante a execução do estágio? Após o estágio quais as perspectivas para o seu futuro profissional?

Os resultados foram tabulados no Programa Microsoft Excel para uma análise estatística descritiva.

\section{RESULTADOS E DISCUSSÃO}

Com a metodologia descrita obtemos os seguintes resultados, ao questionarmos sobre a importância do estágio no curso de licenciatura plena em Ciências Agrárias, dos 50 entrevistados 98\% afirmaram que o estágio foi importante, até porque contribui na aquisição de conhecer a realidade no cotidiano escolar, porém $2 \%$ relataram que não foi tão significante o estágio (Figura 1).

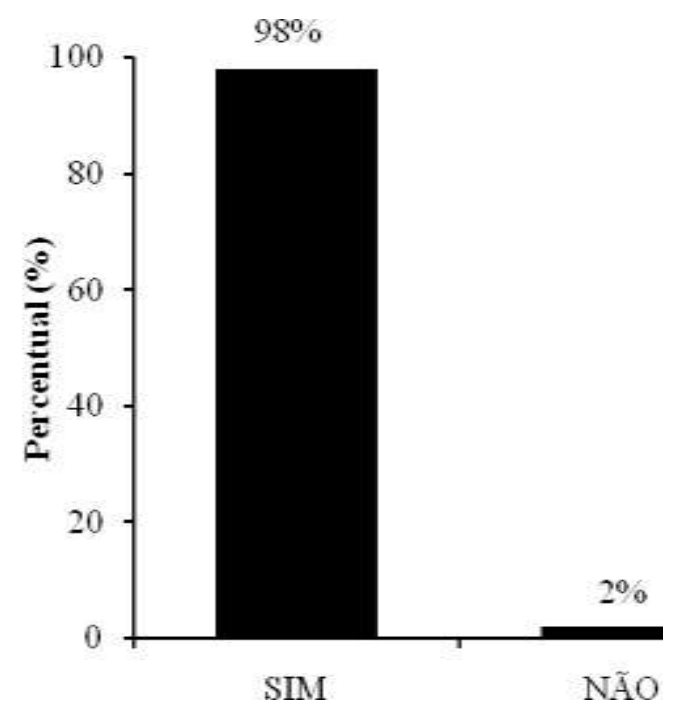

Figura 1 - Percentual de alunos que acham de grande importância o estágio para a formação docente. UEPB, Catolé do Rocha-PB, 2016.

Daí a necessidade desse componente para a formação docente. O Estágio Supervisionado poderá ser um agente na formação do professor, caracterizando-se como objeto de estudo e reflexão. Ao estagiar, o futuro professor passa a enxergar a educação com outro olhar, procurando entender a realidade da escola e o comportamento dos alunos, dos professores e dos profissionais que a compõem (JANUÁRIO, 2008).

Além disso, é preciso uma visão crítica dos princípios que fundamentam sua prática, dos 
objetivos por ela visados, dos compromissos por ela requeridos.Os estudos sobre profissão docente, qualificação, carreira profissional, possibilidades de emprego aliados a ética profissional, competência e compromisso, deverão integrar o campo de conhecimentos trabalhados no estágio por meio de procedimentos de pesquisa, que tenha por objetivo a construção da identidade docente. Para essa construção, contribuem também os estudos e as análises da prática pedagógica que ocorre nas escolas a partir dos aportes dos campos do currículo, didática e prática de ensino (PIMENTA; LIMA, 2008).

Ao indagar os entrevistados com relação se possuíam ou não afinidade com o ambiente escolar após o estágio, 92\% afirmaram que sim e também comentaram que o estágio impulsionou a vontade de lecionarem, porém apenas $8 \%$ falaram que não encontraram afinidade com o futuro campo de atuação (Figura 2).

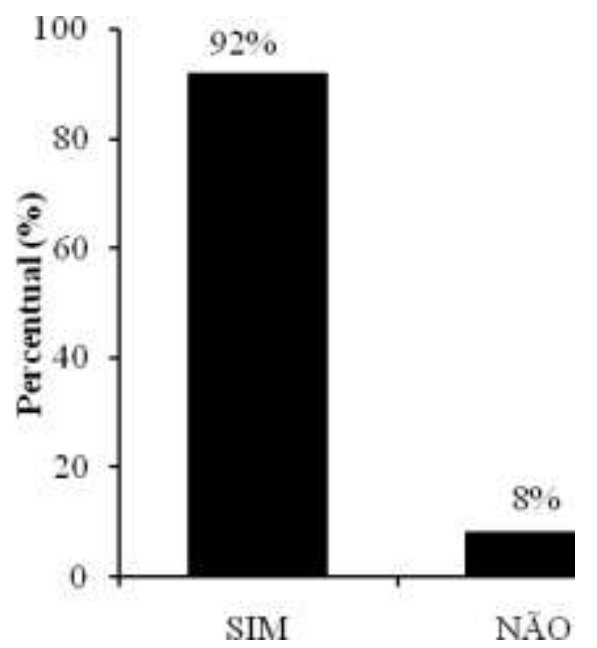

Figura 2 - Percentual de alunos que encontraram no estágio afinidade no seu futuro campo de atuação.

Isso é observado devido a alguns alunosestagiários não cursarem o curso pretendido, ou não cumprirem o estágio com responsabilidade e compromisso de investigar os pontos negativos da escola a fim de provocar mudanças significativas na instituição. O estágio é um espaço privilegiado de questionamento e investigação, sua atividade na escola tem por finalidade buscar mudanças, colher dados para denunciar falhas e insuficiências da educação. $\mathrm{O}$ estágio ainda que transitório, é um exercício de participação, de conquista e de negociação do lugar do estagiário na escola (OLIVEIRA; HERNÁNDEZ, 2005).

Interrogando sobre as subdivisões do estágio no curso de Licenciatura Plena em Ciências Agrárias, 60\% confirmaram relevante para a melhor compreensão e adequação das atividades, contudo $40 \%$ relataram que não era um fator relevante essa subdivisão e confessaram que poderiam estar realizando outras atividades durante o tempo gasto nessas etapas de estágio.

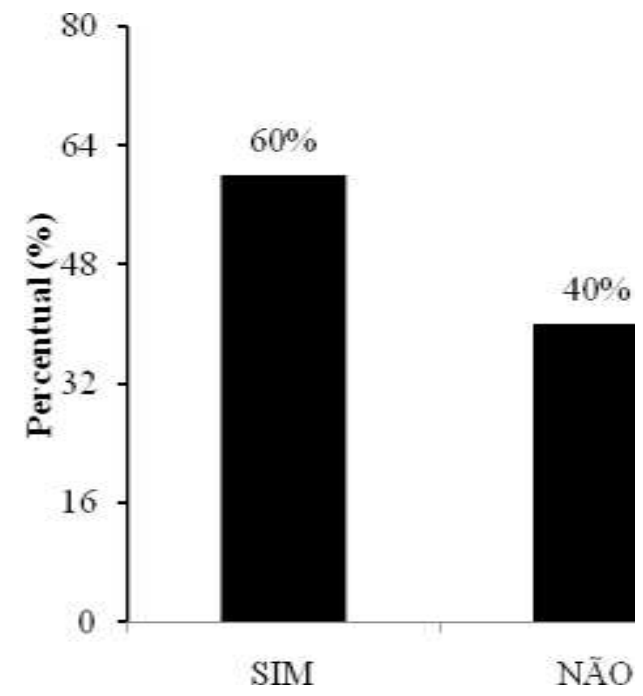

Figura 3 - Percentual de alunos que afirmam a importância da metodologia da subdivisão do estágio em quatro fases (duas observações e duas intervenções).

$$
\text { Segundo Freitas (2013) }
$$

\section{RESOLUÇÃO/UEPB/CONSEPE/XX/2013}

regulamenta e define carga horária e ementas dos componentes

curriculares 
Supervisionado nos cursos de Licenciatura da UEPB, no Art. $5^{\circ}$ diz que a carga horária do componente curricular Estágio Supervisionado é de 400 horas, sendo indispensável para obtenção do diploma, o Estágio Supervisionado no curso de licenciatura plena em Ciências Agrárias, subdividido em quatro etapas de 150 horas cada.

Nessas etapas o Estágio Supervisionado I e o Estágio Supervisionado II são cumpridos em escola pública municipal e estadual. Sendo no Estágio Supervisionado I realizada observação da vivência da realidade escolar e planejamento e no Estágio Supervisionado II a intervenção. A disciplina observada e ministrada pelos estagiários é das Ciências Naturais (Ciências). Os assuntos abordados na disciplina de Ciência trabalham o meio ambiente incluso no cotidiano dos alunos. Jáo Estágio Supervisionado III e o Estágio Supervisionado IV são realizados na Escola Agrotécnica do Cajueiro que faz parte do CCHA. O Estágio Supervisionado III érealizado observação da vivência da realidade escolar e planejamento do Ensino Médio Integrado e profissionalizante no curso técnico em Agropecuária e no Estágio Supervisionado IV a intervenção. Sendo as disciplinas ministradas na área de Ciências Agrárias (FREITAS, 2013; FERREIRA et al., 2015).

$\mathrm{Na}$ subdivisão do estágio eram realizadas as seguintes atividades em cada momento:

Observação: Atividades de observação e análise de documentos; Observação do espaço escolar - localização e infraestrutura - visando conhecer os aspectos físicos e recursos didáticos da escola e importância dessa escola na comunidade local; Observação do fluxo de pessoas no espaço escolar - horários de funcionamento, intervalos, entradas e saídas de pessoas - visando conhecer como as pessoas se movimentam naquele espaço; Observação das aulas - comportamento dos alunos em sala de aula, didática do professor, interação professoraluno-conteúdo - visando conhecer a dinâmica de uma sala de aula, levantar e problematizar situações de ensino-aprendizagem; Leitura do Projeto Pedagógico e do Regimento da Escola e outros documentos oficiais - visando conhecer e analisá-los e verificar se são cumpridos.

Intervenção: Estudo e Planejamento de aulas - visando desenvolver recursos didáticos para promover a aprendizagem de determinado conteúdo, subsidiado por um referencial teórico; Execução desse planejamento; Avaliação do planejamento executado - visando avaliar a proposta de aula, procurando refletir sobre os pontos positivos e os negativos, sobre o que poderia mudar.

Esse momento de intervenção permite ao estagiário estabelecer paralelos entre o discurso teórico (do que aprendeu nas unidades curriculares de formação básica Prática Pedagógica I, II e III, Filosofia da Educação, Psicologia da Educação e etc., além dos conteúdos teóricos das disciplinas voltadas à Ciência (área Agrária) e o prático do fazer docente.

Sendo assim, com essas subdivisões os alunos não se sobrecarregam tanto com as atividades de estágio e ainda podem aprimorar suas habilidades durante a observação, já que observação compõem criticidade dos colegas professores.

O estagiário não deve somente cumprir as suas cargas horárias do curso, mas extrapolar 
intervindo mudanças na própria metodologia do ensino/ aprendizagem. Assim com diz Guedes (2009), há necessidade que o Estágio Supervisionado extrapole o limite do empírico, das atividades isoladas com o objetivo de cumprir a carga horária. Só assim a teoria e a prática caminharão juntas.

Embora, o curso seja vinculado ao campo educacional (licenciatura) ainda questionamos os estagiários no requisito de outros campos de atuação para estágio, já que segundo Freire (1996) lecionar não necessita ser em uma escola, existem vários ambientes que compõem transferência de conhecimento.

Baseado nisso, indagamos sobre atuação de estágio vinculada a outro campo como EMATER, empresas agrícolas ou fazendas. Com isso, $80 \%$ gostariam de vincular o estágio em sala de aula com outros campos de atuação. Apenas 20\% dos entrevistados declaram satisfeitos somente no ambiente de sala de aula (Figura 4).

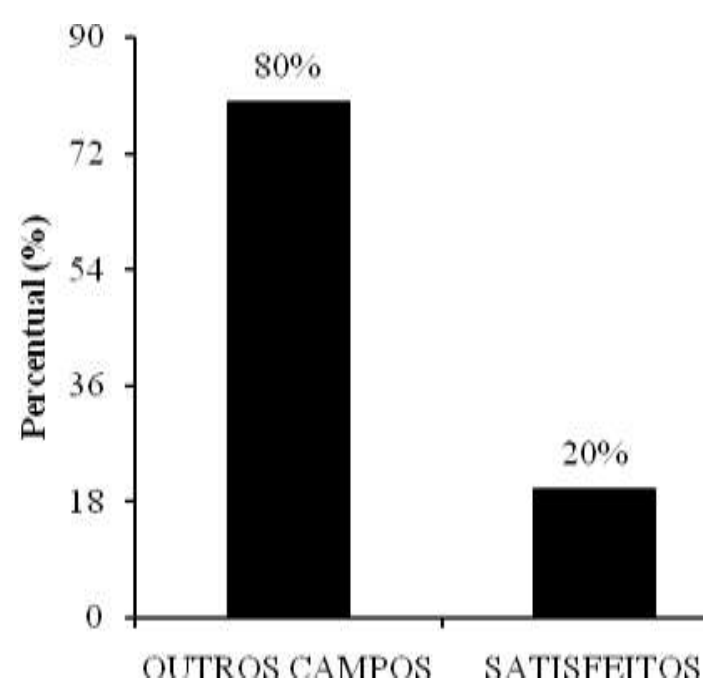

Figura 4 - Percentual de alunos que preferem a vinculação do estágio em outros campos de atuação e os que se encontram satisfeitos com o estágio.
O Estágio Curricular Supervisionado num curso de licenciatura consiste em um processo planejado, visando à integração entre conhecimentos práticos e conhecimentos teóricos que complementem a formação acadêmica do aluno. O estágio supervisionado poderá realizarse em instituições públicas ou privadas de ensino e constitui-se de atividades de aprendizagem social, profissional e cultural, proporcionadas ao estudante pela participação em situações reais de vida e de trabalho (PIMENTA; LIMA, 2008).

A relevância da vinculação do estágio em sala de aula e campo está interligada ao que afirma Libâneo (2008), onde faz necessário educar para a participação social, para o reconhecimento das diferenças entre os vários grupos sociais, para a diversidade cultural, para os valores e direitos humanos. Isso significa, também, que menor ou maior acesso à educação escolar e a outros bens culturais determina a qualidade da participação popular nos processos decisórios existentes na sociedade civil.

Ainda assim, com base no questionário que foi utilizado nessa pesquisa, ao perguntar as dificuldades encontradas durante o estágio, $58 \%$ dos alunos tiveram como obstáculo a falta de recursos didáticos na escola, tais como, livros didáticos, data shows, entre outros, $35 \%$ dos alunos revelaram como dificuldade a desmotivação dos discentes na sala de aula, $5 \%$ afirmaram a falta de domínio com a turma no estágio e $2 \%$ se sentiram inseguros para repassar o conteúdo ministrado da disciplina (Figura 5).

Isso denota o quanto as escolas necessitam de mais investimentos e o estagiário como futuro professor e mediador do conhecimento precisa se adaptar aos desafios que encontrará no seu 
campo de atuação, por isso estabelecer relação entre teoria e prática é de fundamental importância para aperfeiçoar sua metodologia de ensino, auxiliando nos obstáculos que não são poucos ao longo da vida profissional.

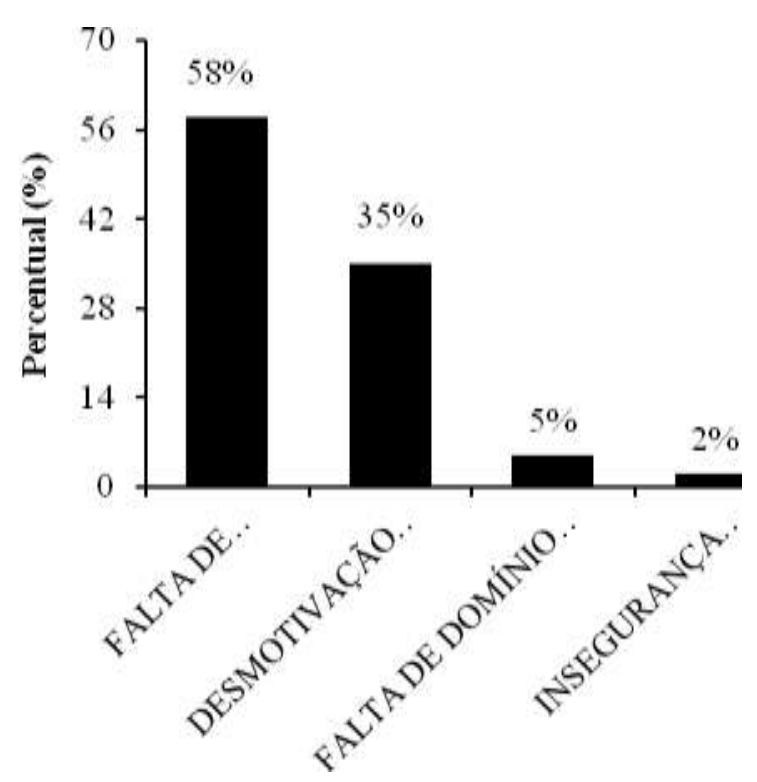

Figura 5 - Percentual referente às dificuldades dos alunos encontradas durante o estágio.

Esses empecilhos relatados tanto na infraestrutura da escola, quanto na desmotivação de alunos e professores refletem em frustações para alguns alunos estagiários, durante a observação e intervenção sendo paradigmas que fazem o estagiário refletir se realmente está cumprindo seu papel como agente transformador daquele ambiente. Segundo Pimenta (1994) o estagiário reflete o que ensinar de modo que os alunos aprendam? Que lógicas de organização curricular e de gestão escolar favorecem a aprendizagem? Como garantir que todos os alunos se apropriem dos instrumentos necessários para se situarem no mundo? Como estabelecer os vínculos entre conhecimento e formação cultural, desenvolvimento de hábitos, atitudes, valores? Para que ensinar? Que materiais equipamentos, mídias, precisam ser mobilizados no processo de ensino?

Com isso, para finalizar ao questionarmos sobre o futuro desses estagiários após o término do curso, a maioria, ou seja, 50\% relataram que não possui nenhuma expectativa sobre se irá atuar no campo de formação, como empecilhos relataram a falta de oportunidades para atuarem, pois a aceitabilidade nas escolas de educação básica infelizmente muita escassa, visando apenas os profissionais formados em outras licenciaturas, além disso,nas escolas técnicas existem poucas escolas técnicas agropecuárias na região, com isso, a dificuldade no deslocamento para outras localidades que possuem oportunidades é um dos empecilhos (Figura 6).

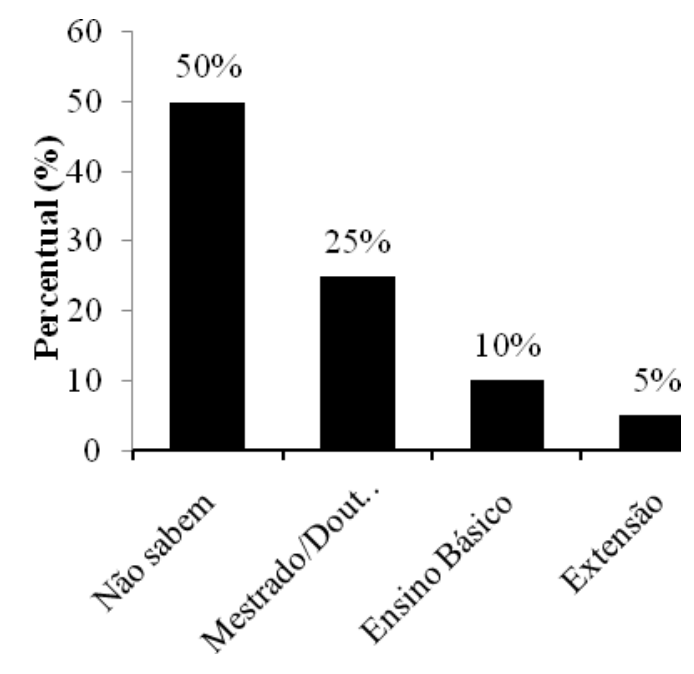

Figura 6 - Percentual referente às perspectivas para o futuro profissional.

$25 \%$ afirmam que irão prosseguir a vida acadêmica na expectativa de melhores oportunidades de emprego futuras e maior patamar social. $10 \%$ relataram que já atuam ou tem expectativa de trabalharem em escolas de 
ensino básico. $5 \%$ pretendem trabalhar na área extensionista.

Sabe-se que o profissional licenciado em Ciências Agrárias é habilitado para atuar em três pilares: educacional básico na disciplina de Ciências Naturais, em escolas técnicas agropecuárias e extensão rural. Contudo, a falta de oportunidades ainda é gigantesca para esses profissionais, diminuindo assim o número de profissionais que atuam na área, após a conclusão do curso.

\section{CONCLUSÕES}

O trabalho realizado alcançou os objetivos propostos, percebendo que o estágio é importante para o aperfeiçoamento de ensinamentos que são adquiridos durante o curso, sendo esse momento a possibilidade do discente participar ativamente no processo de ensino-aprendizagem e enxergarse como docente através do desenvolvimento e resoluções das atividades.

O estágio possibilita o licenciando vivenciar um ambiente que passa por constantes mudanças e possui ligações intrínsecas com diversos outros meios de socialização (relação professor $\mathrm{x}$ aluno, aluno $\mathrm{x}$ aluno, docente $\mathrm{x}$ conteúdo, família $\mathrm{x}$ escola $\mathrm{e}$ cidadão $\mathrm{x}$ sociedade), compensando saberesadquiridos na observação. Contudo, ainda necessita de modificações para ampliar o leque de profissionais que concluem o curso e ingressam na carreira profissional do curso. Desta forma, o estágio prepara os licenciados em Ciências Agrárias para o futuro mercado de trabalho,bem como, para a vida.

\section{REFERÊNCIAS}

FERREIRA, I.S.; MELO, D.R.M.; SILVA JÚNIOR, F.P.; ROCHA, I.V.; SILVA, F.P. A teoria e a prática pedagógica do estágio supervisionado: Estudo de caso. Revista da Universidade Vale do Rio Verde, v. 13, n. 1, p. 99-113, 2015. http://dx.doi.org/10.5892/ruvrd.v13i1.1846

FREIRE, P. Pedagogia da autonomia: saberes necessários à prática educativa. São Paulo: Paz e Terra, 1996 (Coleção Leitura). 165p.

FREITAS, M. Importância do estágio supervisionado para a formação docente do licenciado em Ciências Agrárias. 2013. 12 p. Trabalho Acadêmico Orientado (Graduação em Ciências Agrárias) - Universidade

Estadual da Paraíba, 2013. [acesso em: 20 de novembro de 2017]. Disponível em: <

http://dspace.bc.uepb.edu.br:8080/xmlui/handle/12345 6789/4542>.

PIMENTA, S.G. GONÇALVES, C. L; Revendo o ensino de $2^{\circ}$ grau, propondo a formação do professor. São Paulo: Cortez, 1990.

GUEDES, S. T. R. A Relação Teoria e Prática no Estágio Supervisionado. In: IX Congresso Nacional de Educação - EDUCERE. III Encontro Sul Brasileiro de Psicopedagogia. Paraná: PUCPR, 2009.

JANUARIO, G. O Estágio Supervisionado e suas contribuições para a prática pedagógica do professor. In: Seminário de história e investigações de/em aulas de matemática, 2, 2008, Campinas: Gds/FEUnicamp, 2008. v. único. p. 1-8.

LIBÂNEO, J. C. Organização e gestão da Escola: Teoria e Prática. 5 Ed. Revista e ampliada - Goiânia: MF Livros, 2008.

OLIVEIRA, M.O.; HERNÁNDEZ, F. (orgs). A formação do professor e o ensino das artes visuais. Santa Maria: UFMS, 2005.

PERRENOUD, P. Dez novas competências para ensinar. Porto Alegre: ARTMED, 2000. 192p.

PIMENTA, S.G. (Org.). O estágio na formação de professores: unidade, teoria e prática? São Paulo: Cortez, 1994.

PIMENTA, S. G; LIMA, M. S. L. Estágio e Docência. 5 Ed. São Paulo: Cortez, 2008.

Cortez, 2010.

Estágio e Docência. 6. Ed. São Paulo: 


\begin{tabular}{l}
\hline Valéria Fernandes de Oliveira Sousa \\
Mestre em Horticultura Tropical na Universidade \\
Federal de Campina Grande e Licenciada em \\
Ciências Agrárias na Universidade Estadual da \\
Paraíba. Unidade Acadêmica de Agrárias.
\end{tabular}

\section{Gisele Lopes dos Santos}

Mestranda em Horticultura Tropical na Universidade Federal de Campina Grande e Licenciada em Ciências Agrárias na Universidade Estadual da Paraíba. Unidade Acadêmica de Agrárias.

\section{Luana Muniz de Oliveira}

Mestranda em Horticultura Tropical na Universidade Federal de Campina Grande e Licenciada em Ciências Agrárias na Universidade Estadual da Paraíba. Unidade Acadêmica de Agrárias.

\section{Marília Hortência Batista Silva Rodrigues}

Mestranda em Horticultura Tropical na Universidade Federal de Campina Grande. Unidade Acadêmica de Agrárias.

\begin{tabular}{l}
\hline Maria Amanda Vieira de Almeida \\
Graduada em Licenciatura Plena em Ciências \\
Agrárias na Universidade Estadual da Paraíba. \\
Departamento de Agrárias e Exatas
\end{tabular}

